f. med. Genet. (1969). 6, 442.

\title{
A New Mutant Gene Possibly Carried Simultaneously by Two Distinct Gametes
}

\section{EUGÈNE SCHREIDER}

\section{From Laboratoire d'Anthropologie Physique (Ecole Pratique des Hautes Etudes), Laboratoire de Biométrie Humaine}

(Centre National de la Recherche Scientifique), Paris, France

Thanks to the help of one of my pupils, a native of Madagascar, I was able to collect the following data concerning his own family (Fig.). Both parents are 'normal' and so are all uncles and aunts. The parents have 11 children, 5 boys and 6 girls. Among the children there are two dizygotic unlikesexed twins. Both twins have a fourth distal phalanx on their middle fingers. The female twin has no children; she is still unmarried. Her twin brother has a 'normal' wife and 4 children, all with a fourth phalanx on the middle fingers.
Obviously, the anomalous trait is hereditary and behaves as if it were determined by a dominant gene with a strong penetrance. Seemingly a mutation occurred in the gametes of one of the parents. As the fourth phalanx appeared for the first time in two dizygotic twins we can suppose that the mutant gene was produced at least twice and that it was present simultaneously in two distinct gametes. Such an occurrence, even if very infrequent, cannot be discarded as unlikely, though this is of course not 8 the only possible explanation.

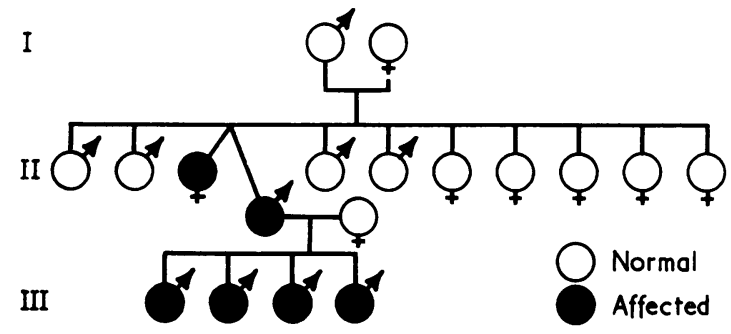

FIG. Inheritance of a fourth phalanx on the middle fingers.

Received July 14, 1969. 